\title{
How SMEs Can Create Value for Customers through Emergency Logistics and Human Resource Management under Unexpected Events
}

\section{-Service-Dominant Logic Perspective}

\author{
Qian Li*, Xiaoyan Zhang \\ School of Economics and Management, Shanghai Maritime University, Shanghai, China \\ Email: *595165664@qq.com
}

How to cite this paper: Li, Q., \& Zhang, X. Y. (2021). How SMEs Can Create Value for Customers through Emergency Logistics and Human Resource Management under Unexpected Events. Open Journal of Business and Management, 9, 255-267.

https://doi.org/10.4236/ojbm.2021.91014

Received: December 14, 2020

Accepted: January 17, 2021

Published: January 20, 2021

Copyright $\odot 2021$ by author(s) and Scientific Research Publishing Inc. This work is licensed under the Creative Commons Attribution International License (CC BY 4.0).

http://creativecommons.org/licenses/by/4.0/

\begin{abstract}
The worldwide impact of the COVID-19 outbreak was huge, and with the joint efforts of the whole country, the epidemic was basically controlled in China, but the outbreak gave us a long-lasting reflection. The outbreak has had a significant impact on our economic development and people's lives. For SMEs with small market share and poor risk resistance, it is a difficult problem to deal with the outbreak, and the lack of crisis awareness and contingency plans of most SMEs makes the survival crisis of SMEs deepen greatly, so it is necessary to explore how SMEs can deal with the outbreak. Since there are different and unevenly distributed resources in China, emergency logistics in response to emergencies is particularly important. This paper examines how SMEs can achieve emergency logistics and human resource management to create value for customers in the context of emergencies from the perspective of service-dominant logic, in order to provide solutions for SMEs to escape from the dilemma of survival. The service-dominant logic focuses on the process of co-creation of value through continuous interaction between producers and consumers, and believes that value co-creation can be achieved through healthy and effective interaction between enterprises and customers. In this paper, we take COVID-19, a social hotspot, as the background to discuss how SMEs can do a good job in emergency logistics and human resource management for their own better development in the face of emergencies.
\end{abstract}

\section{Keywords}

SMEs, Emergency Logistics, Human Resource Management, 
Service-Dominant Logic

\section{Introduction}

COVID-19 has touched everyone's heart since the major outbreak, a sudden crisis that has left our country facing huge losses in human and material resources and financial resources. During this outbreak, many small and medium-sized enterprises faced an existential crisis because they did not view the crisis correctly and lacked crisis response strategies. Today, due to the tight coupling of organizations and technology, the failure of one organization may in turn lead to the failure of others in a manner known as cascading failure (Smith, 1990). Small and medium-sized enterprises (SMEs) are often at the center of the storm by the "ripple effect" of many of these crises, and Spillan and Hough find that SMEs focus primarily on the types of crises they have experienced before, underestimating the risk of events they have not experienced before (Spillan \& Hough, 2003). While it is true that SMEs have more difficulties in facing crises, they are more receptive to changes in strategic decisions than larger organizations, and Alesch et al. (2001) found that those who took positive action to improve their business potential were small businesses (Alesch et al., 2001). Therefore, as the old saying goes, "A small boat is a good place to turn around", SMEs have some advantages in adopting new initiatives and accepting new ideas to make new changes. The outbreak of the epidemic has made both human resources and relief supplies in short supply, and with Wuhan, Hubei Province being the hardest hit area in China, the government immediately blocked the city gates after the outbreak, so how to get relief supplies to Wuhan smoothly, quickly and safely is the issue at hand. "Emergency logistics" is defined as a special logistic activity in response to serious natural disasters, public health emergencies, public security events and military conflicts and other emergencies to ensure the urgent needs of materials, personnel and funds (Ou et al., 2004). The specificity of emergency logistics is expressed in the word emergency, which may be of little use in most cases, but will play a powerful role once it encounters unexpected events, and can minimize the adverse effects brought by sudden events. In addition, in recent years, with the rapid development of the economy, business models continue to innovate, consumer consumption activities have changed dramatically, the rise and development of e-commerce, greatly promote the consumption of residents, and drive a logistics industry chain, China's logistics industry development momentum, but are the main purpose of profit logistics, mainly to transport goods and materials. With the development of logistics industry, the research related to logistics industry also gradually increases, such as logistics supply chain research, green logistics-related research, but the research related to emergency logistics is less, and the research about the emergency logistics and human resource management of small and medium-sized enterprises in the 
context of emergencies is even less. In addition, human resources are an important resource on which economic development depends. Whether the quantity of human resources is sufficient and whether the ability is qualified is a question that every enterprise needs to think about, and a sufficient reserve army of human resources is a guarantee for enterprise development and expansion, and good quality of human resources is a key part of enterprise development. Therefore, this paper studies the emergency logistics and human resource management of small and medium-sized enterprises under unexpected events is both theoretical and practical significance.

Vargo and Lusch first introduced the concept of service-dominant logic, arguing that as the times evolve, a new perspective emerges where "services" dominate rather than "goods" dominate. Service-dominant logic is a more robust framework for service science than the traditional commodity dominant logic (Lusch, Vargo, \& Wessels, 2008). The service-dominant logic theory proposes that value is created through the interaction between the customer and the firm, rather than simply the completion of an exchange of goods. The significance of this interaction lies not in the transfer of output ownership (as in G-D logic) but in the interaction itself, in serving the needs of the customer, as experienced by the customer in the unique context of his or her own life and the purpose of seeking market exchange (Grnroos, 2006). Applying the service-dominant logic means that the company is not limited to making value propositions, but is actively and directly involved in the realization of value for the customer by co-creating possibilities and gaining access to opportunities through the value co-creation in the process of interaction with the customer (Groenroos, 2008). The provision of products or services by SMEs to customers is a process that requires active interaction between enterprises and customers. Based on this, this paper hopes to explore how SMEs can realize emergency logistics and human resource management in the context of emergencies in order to create value for customers and ultimately achieve the development goals of SMEs from the perspective of service-dominant logic.

\section{Literature Review}

\subsection{Emergency Logistics}

Since the SARS incident in 2003, Chinese scholars began to pay attention to the research of emergency logistics guarantee mechanism and the exploration of national emergency logistics system under the sudden public health event (Ruolan \& Yan, 2020). In the following years, scholars in China also carried out a series of studies on this issue. Ou Zhongwen et al. took the establishment of a complete emergency logistics system as the goal and exhaustively proposed a guarantee method to improve the emergency logistics management mechanism (Ou et al., 2005). Hui Chen gives a detailed introduction to the existing emergency logistics system in China and gives optimization suggestions considering the holistic nature (Hui, 2014). Other scholars have conducted relevant studies from a huma- 
nitarian perspective. Combining the relevant studies and the epidemic examination, it is found that although China's emergency logistics system has been gradually improved, some problems have been highlighted, such as poor transportation of materials and broken transportation supply chain. Therefore, there are still many problems in emergency logistics in China that need to be solved. When an emergency occurs, time is the most critical, timely implementation of rescue, timely delivery of rescue materials, timely rescue work is of paramount importance, shorter rescue time means more lives can be saved and overall losses can be reduced. Therefore, maximum efforts should be made to shorten the rescue response time so that injured people can receive the necessary first aid in the shortest possible time. Rescue work (including the timely delivery of supplies, medical personnel in place, medical supplies, etc.) can not be carried out smoothly without the hard work of each staff member, human resources are an important resource under the emergency, so it is necessary to give all staff members in addition to the work environment and personal safety protection, but also to give material rewards to stimulate enthusiasm for work and spiritual rewards to stimulate a sense of mission.

\subsection{Service-Dominant Logic}

In fact, although emergency logistics is characterized by suddenness, weak economy, uncertainty and unconventionality, it still belongs to the service industry at its root. For SMEs, it is the primary issue to do a good job in emergency logistics and talent security management under unexpected events to ensure the normal supply of production materials and the normal operation of the whole enterprise. Broadly speaking, there are two views in considering services. One view is that commodities (tangible outputs with embedded value) are the primary focus of economic exchange, while "services" (usually plural) can be 1) a restricted (intangible) good or 2) an additional product that adds value to a good (Vargo and Lusch, 2008). Vargo and Lusch call this a commodity-dominated logic (G-D logic). The second view sees "service" (singular) as a process of doing something for another party that does not involve goods, and identifies service as the primary focus of exchange activity. Vargo and Lusch (2004) refer to this logic as service-dominated (S-D) logic. G-D logic views producers as value creators and consumers as value destroyers, while S-D logic views customers as always cocreators (joint or collaborative contributors) of value (Greer, Vargo, and Lusch, 2016). With the development of the economy and the advent of the Internet era, which closely links producers, suppliers, distributors agents and consumers, the service dominant logic perspective is gaining importance. the development of S-D logic allows us to more clearly view all social and economic actors as general actors in resource integration, service provision and value co-creation. Moreover, each participant in the activities of resource integration, service delivery, and value creation is dynamic and active, thus exhibiting actionable resources (Lusch and Vargo, 2012). Consumers are becoming more and more prominent 
in economic activities, and many companies are paying more attention to their own creativity. The consumer is not only the final link of consumption, but should be present in all aspects of consumer activity. To gain competitive advantage, companies must integrate the consumer into all aspects of design, production, production and consumption, making the consumer a co-creator of value.

Small and medium-sized enterprises have the disadvantages of small size and lack of capital, but because of their small business scope and few business processes, they have more contact points with consumers, so they are more able to communicate with them, and consumers are more likely to participate in value creation. Nowadays, companies are paying more and more attention to creating value together with consumers, focusing on customer participation, improving customer experience, and ultimately creating value for customers.

\section{Research Method}

The Case Analysis Method, also known as the Case Study Method, was developed by Harvard University in 1880 for the purpose of training executives and has since been developed into what is known today as the "Case Study Method". The case study approach analyzes all aspects of a typical case study, such as its history, operating model, main business and profitability, marketing strategy, competitive strategy, etc., in order to derive general strategies that can influence other companies. The case study method is to analyze a phenomenon or a thing, so as to draw general and universal laws of a phenomenon or a thing, and to deduce deeper research conclusions from it. In this paper, in order to clarify the problems and laws of emergency logistics and human resource management of SMEs under emergencies, we analyze the problems and coping strategies faced by logistics enterprises in China during the epidemic in order to compile strategies for SMEs to cope with emergencies.

After the outbreak of the epidemic in Hubei Province, people from all walks of life actively lent a helping hand, donated money and materials, and sent joint assistance to Hubei by sea, land and air. According to the statistics of the Ministry of Transport, from January 27 to February 29, 2020, a total of 560,100 tons of epidemic prevention materials and living materials were delivered to Hubei, and $1,186,600$ tons of production materials, such as coal and fuel, were delivered from all over the country. Transportation means such as highways, railroads, civil aviation systems and ships also kept transporting relief materials to Hubei Province. The specific data are shown in Table 1.

In addition, from the full help platform freight, data can be seen on January 13, 2020 is a cut-off point. before January 13 to Hubei goods mainly to building materials, food and beverage, coal minerals, timber and mainly, after January 13 , vegetables, fruits and other daily food freight volume soared, of which vegetables accounted for $10.4 \%$ of all goods shipped to Hubei, listed in the first place of security supplies. (Data source: Cargo data from the Full Help platform). From the 
Table 1. List of transportation modes and cargo goods delivered.

\begin{tabular}{|c|c|c|}
\hline $\begin{array}{l}\text { Shipping } \\
\text { Methods }\end{array}$ & Highway & Railroad \\
\hline $\begin{array}{c}\text { Number of supplies } \\
\text { delivered }\end{array}$ & $\begin{array}{c}\text { A total of } 243,700 \text { tons of epidemic } \\
\text { prevention materials and related } \\
\text { living materials were delivered } \\
\text { to Hubei }\end{array}$ & $\begin{array}{l}\text { A total of } 10,154 \text { batches and } 202,600 \\
\text { tons of prevention and control security } \\
\text { materials were shipped, including } \\
6,465 \text { batches and } 28,400 \text { tons of } \\
\text { epidemic prevention items }\end{array}$ \\
\hline Shipping Methods & Civil aviation & Cargo Vessels \\
\hline $\begin{array}{c}\text { Number of supplies } \\
\text { delivered }\end{array}$ & $\begin{array}{l}\text { Cumulatively, } 584 \text { flights were } \\
\text { guaranteed to Hubei, } 732,900 \text { pieces } \\
\text { of prevention and control materials } \\
\text { were delivered, totaling } 0.72 \text { million } \\
\text { tons }\end{array}$ & $\begin{array}{l}29,348 \text { inbound and outbound } \\
\text { vessels, including } 388 \text { vessels carrying } \\
\text { key materials in Wuhan waters, } \\
\text { transporting more than } 1,014,000 \text { tons } \\
\text { of coal, } 173,000 \text { tons of fuel oil } \\
\text { and } 63,000 \text { tons of grain. }\end{array}$ \\
\hline
\end{tabular}

Data source: According to the Ministry of Transport statistics.

point of view of the output of goods, vegetables are mostly shipped to Hubei from Yunnan, Henan, Shandong and other places, of which Kaifeng, Henan, is the largest city in the country to aid Hubei vegetables. Fruits are mainly transported from the south of China, such as Guangxi, Yunnan and Guangdong, and the fruits shipped to Hubei from Guangxi alone account for $52 \%$ of the total number of the top ten cities. Whether it is epidemic prevention supplies or daily food, what we can see is a surprising and admirable data, but behind the data is the concerted efforts of our country, representing the national people's concern for Hubei Province, representing the efficiency and style of our country's thunderbolt. Just as "food and grass come first before the soldiers move", emergency relief supplies such as medical masks, protective clothing, goggles, medical alcohol and disinfectants became important support for the emergency during the epidemic. In this epidemic prevention and control process, emergency logistics played an important role in the prevention and control of the epidemic, whether it was the production, procurement, transportation and distribution of key epidemic prevention materials, or the supply of materials to maintain the daily production and living of all front-line staff and patients.

\section{Problems of Logistics Enterprises under Emergencies and Countermeasures}

\subsection{Problems of Logistics Enterprises under Emergencies}

The sudden outbreak of COVID-19 touched the hearts of the nation up and down, and for a while, the society was pressed the pause button, and the formerly prosperous streets became cold, although in this big test China curbed the spread of the epidemic with strong execution and combat power. But at the same time, it also highlighted some shortcomings of our emergency logistics system. 
The most important test of the country's reaction and action is to have sufficient human, material and financial resources to guarantee the supply of materials, timely treatment of people and basic livelihood protection. Rescue supplies from all over the country as well as living supplies were rushed to Hubei at the first time, and rescue workers from all over the country went to the front line to fight against the epidemic. It is very important to do a good job in emergency logistics and human resources management under emergencies. General Secretary Xi Jinping stressed at the 12th meeting of the Central Committee for Comprehensively Deepening Reform that we should improve the unified emergency material security system and make emergency material security an important part of the national emergency management system construction. This requires us to pay great attention to this, strengthen top-level design, and study and build an efficient and effective emergency logistics system to better prevent problems before they occur (Yuan, Zhang, \& Chen, 2020). It can be seen that the construction and improvement of emergency logistics system are very important, and the difference between emergency logistics and ordinary logistics is shown in Table 2. A sound logistics system can not be built without the guarantee of human resources, so it is important to study the logistics and human resources management in response to emergencies. However, it is undeniable that China's system mechanism in this area still needs to be perfected, and the next main elaboration is the main problems in emergency logistics and human resource management in China.

1) Mismatch between emergency logistics facilities and emergency requirements, and low efficiency of logistics delivery

Emergency logistics facilities mainly include infrastructure construction, such as highway maintenance, water, land and air as well as pipeline coordination of transport, etc., which requires a lot of human and material resources, financial resources, and requires the unified deployment of resources by the state. Emergency logistics equipment mainly includes warehousing equipment, to ensure the integrity of the stored goods in more than 98\%; information management system, including goods in transit tracking system, GPS positioning system, office automation system, etc. Specifically, it includes automatic packing machine, film winding machine, etc. China's emergency logistics facilities and equipment construction is not perfect. For example, in the SARS rescue work in 2003,

Table 2. Comparison table between emergency logistics and ordinary logistics.

\begin{tabular}{lcc}
\hline Name & Emergency logistics & General Logistics \\
\hline Fluid & Relief goods mainly & General merchandise \\
Carrier & Both fixed and temporary locations & Stationary places \\
Flow direction & The final flow to the affected people & Final flow to consumers \\
& in the disaster area
\end{tabular}


relevant government departments and related organizations in China faced problems such as huge quantity of emergency materials allocation, slow collection of materials, and difficult organization and transportation management. Many emergency logistics materials were difficult to meet the requirements of reaching the disaster relief site for the first time due to transportation and storage difficulties. Therefore, the construction of related facilities and equipment, including the construction of roads, the arrangement and construction of logistics sites, the purchase of freight vehicles, and the improvement of information systems, are all necessary prerequisites for the timely and smooth implementation of disaster relief work. Although many years have passed since the SARS incident, the experience left behind needs to be kept in mind. Strengthening infrastructure construction and the application of information technology in emergency logistics is an important guarantee for responding to emergencies. No matter which of the above work is carried out, it is inseparable from the participation of human resources, which is the most important resource. Small and medium-sized enterprises due to the lack of funds, logistics related security system is not sound, in response to unforeseen events will fall into the production materials can not arrive in a timely manner, finished products can not be delivered to the hands of customers, and ultimately will destroy the normal production chain of enterprises, resulting in enterprises can not continue to produce or can not be delivered to the hands of customers in a timely manner, so that enterprises can not make ends meet or even on the road to bankruptcy and closure.

2) The functional departments are not closely connected, and information cannot be communicated in time

When an emergency occurs, the timely and accurate transmission of information is the link to carry out the work smoothly, and the accurate and timely transmission of information among various departments can make the work more transparent and visualized, and rapidly improve the work efficiency. Similarly, if the channel of information transmission is blocked or the information is distorted in the process of transmission, it will greatly hinder the process of work. Therefore, it is important to improve the linkage with various functions, standardize the cultivation, and automatically activate the emergency logistics processing system once a certain standardized indicator reaches the alert standard (Luo, 2019). If there is a complete emergency logistics handling system, then a complete linkage system will be formed between the various functional departments of the enterprise to achieve the effect of holding one hair and moving the whole body. Small and medium-sized enterprises themselves have the problem of unclear division of functions and blurred boundaries of relevant departments, which will lead to the inability of enterprises to integrate and mobilize all resources in the context of emergencies and the lack of a clear division of labor mechanism, which will make the work of enterprises fall into chaos and fail to assign responsibilities to people, thus adversely affecting the subsequent work process. 
3) The related technology is not perfect and the degree of intelligence is low

With the development of the economy and the continuous improvement of the level of technology, intelligence has become a common pursuit of change in all walks of life. Digitalization and intelligence have brought convenience and speed to people's life while reducing their cost of living. Due to the many conveniences brought by technology, digitization and intelligence are required to be applied to all aspects of life. China's logistics industry is developing rapidly, but it has not yet reached logistics intelligence. The fundamental reason for this is that the level of technology in China is not perfect enough and the architecture of the logistics system still needs to be improved. This leads to the slow response of emergency logistics. The degree of intelligence is low, logistics information is not updated in a timely manner, no real-time updates are realized, and information lags behind; transportation pressure is high, leading to paralysis of the entire logistics supply chain, which ultimately makes emergency logistics inefficient. Small and medium-sized enterprises should actively invent or use new technologies, get on the "digital" express, continuously improve their technology learning ability and technology application ability, and improve their efficiency. However, the development of new technologies is costly, slow and has a long payback period, and most enterprises do not have sufficient financial support; while using technologies that are already available may fall into the dilemma of constantly copying and imitating the successful path of others and lacking innovation.

4) No special emergency logistics personnel system

China lacks the system structure of emergency logistics talents, after the occurrence of emergencies, most of them are drawn from various regions of the country, and there is no specialized emergency rescue talent guarantee system, which will delay the best rescue time and relate to the success or failure of the final rescue activities. Emergency logistics personnel is the carrier of the implementation of rescue work, the current lack of emergency logistics personnel in China, the need to pay close attention to the training of emergency logistics personnel reserve army. Although SMEs are unable to build an excellent talent system due to various possible factors, with the improvement of national quality and the continuous development of education, the establishment of functional departments composed of professionals and the formulation of perfect rules and regulations, a sound corporate supply chain must be just around the corner.

5) Lack of emergency logistics personnel to supervise the supply chain

Because of the imperfection of the emergency logistics personnel system, the same lack of emergency logistics personnel supervision system is an important part of the lack of supervision, there is a lack of feedback, and thus can not further improve the rescue work. This is not conducive to China's response to emergencies in the post-summary work, if the lack of summary of emergencies and reflective links, then it will not be able to learn lessons, responsibility to the person, reward to the person, the lack of lessons learned summary is not condu- 
cive to China's response to emergencies after. Most SMEs do not have an independent supervision system, although some enterprises may have a supervision department, but often it is only the supervision and management of the superior to the subordinate, and there is not even the existence of a perfect supervision system, resulting in inefficient operation of the enterprise.

\subsection{Analysis of Countermeasures for Problems of Logistics Enterprises under Emergencies}

1) Improve the relevant supporting facilities

Small and medium-sized enterprises should first take customers as the starting point to improve the relevant supporting facilities, from the perspective of customer service, customer convenience, specifically in the daily work of more attention to customer evaluation, so as to find the direction of improvement. As the saying goes, "If you want to do a good job, you must first improve your tools." In order to successfully overcome the crisis, you should first improve the infrastructure, purchase the relevant equipment, and also theoretically require all staff to be familiar with the use of various emergency facilities, and conduct safety checks on various equipment on time.

2) Establish a good internal and external information exchange network

Whether the information can be effectively transmitted within the organization in a timely and accurate manner depends on whether the work can be carried out smoothly; whether the information can be transmitted between internal and external organizations in a timely and accurate manner depends on the efficiency of the enterprise. A good information system will greatly improve the efficiency of work. Small and medium-sized enterprises need to establish a perfect information network, combining various departments within the enterprise and the external stakeholder departments, so as to achieve better operation of the enterprise. Small and medium-sized enterprises can set up an information department within the enterprise, the main task of this department is to collect the latest information of the enterprise, transfer the information among all departments within the enterprise, to ensure that all members of the company are in step, have the same goal, have a common vision and mission, in order to achieve better development of the enterprise.

3) Build an intelligent logistics system

SMEs should invest more in technology and actively develop and explore new technologies where they can. Build a more powerful network information system to realize the interconnection of information between various departments and promote the speed and quality of information exchange. Improve the construction of digital platform and apply the digital platform to all aspects of enterprise work correctly in order to improve the efficiency of enterprise work.

4) Strengthen the construction of talent training system

In the context of the outbreak of emergencies, the training content of SMEs should also be biased toward life safety and property safety. It should also 
strengthen the soft skills training about logistics talents, such as teamwork, leadership and other aspects of training. Training is an important part of human resource management, due to the different nature of work work environment, training content should also be different, in the context of emergency events, in addition to professional knowledge training, but also to increase the training of general safety, emergency rescue and other related knowledge, to ensure the life and health of staff safety at the same time to ensure the smooth development of enterprise work.

5) Adopting flexible work system

Due to the sudden, urgent and occasional nature of emergency work, SMEs can adopt a flexible work system. Flexible work system refers to the system that employees can choose the specific time of work flexibly and independently to replace the uniform and fixed commuting time on the premise of completing the prescribed work tasks (Xue, 2008). Scholars Brauner Corinn and others, explored how different aspects of work time demands (e.g. shift work) and work time control can be brought together in different types of work programs and how they can remain linked to health and work-life balance (Brauner et al., 2019). It can be seen that flexible work system can be used in the work system of small and medium-sized enterprises. Flexible work system can achieve a balance between the work and life of staff without causing waste of human resources, and flexible work system greatly guarantees the freedom of working time of staff and can guarantee the smooth development of enterprise work.

6) Improve performance management system

Performance evaluation plays an important role in the development of enterprises. Reasonable performance evaluation is an effective means to ensure the core competitiveness of enterprises and promote employee innovation (Ren, 2016). The evaluation criteria of performance management in SMEs should be more flexible and nimble. In terms of compensation and benefits, enterprises should, on the one hand, ensure that the necessities of staff are in place in a timely manner and, at the same time, adopt some motivational means to strengthen logistics talents' satisfaction with their jobs and their sense of belonging to the enterprise. You can also adopt some inner motivation, for the outstanding performance during the unexpected events of the enterprise talent to give in appreciation or promotion and other rewards; can also use the material incentive way, reward policy to ensure that each outstanding performance of personnel to give a fair and just reward, and the form of reward and the degree of abundance to make the rewarded personnel relatively satisfied and fair, so as to really play the effect of reward This is the only way to achieve the effect of reward. In short, to enhance the sense of organizational support and loyalty of logistics personnel should be the focus of the staffing plan of the enterprise human resources management department.

7) The country should vigorously cultivate emergency logistics talents

The lack of professional talents in logistics enterprises and the large turnover 
rate are the major problems that China's logistics industry has to face, and there is a shortage of emergency logistics talents when dealing with emergencies, and there is a large gap of emergency logistics talents in China. Therefore, we should strengthen the training and appointment of emergency logistics talents. At present, there are no emergency logistics but only ordinary logistics majors in the disciplines of higher education institutions in China, so we should base on ordinary logistics to highlight the differences of emergency logistics to train emergency logistics talents, especially emergency logistics informatization talents. The government can cooperate with some colleges and universities to carry out directional entrusted training, specifically recruit some emergency logistics students, open emergency logistics courses, and increase the investment in scientific research of emergency logistics to achieve the purpose of training emergency logistics talents.

To sum up, the policies related to emergency logistics and human resource management in China are not sound. SMEs can improve emergency logistics and human resource management by constructing intelligent logistics system, improving information network, adopting flexible working system, staff training, staff motivation and vigorously training new talents.

\section{Conclusion}

At the beginning of 2020, an epidemic outbreak caused the world to pay attention to public health emergencies, whether it is the safe arrival of rescue materials and rescue workers and the successful completion of their work, or the overnight consultation of medical experts after the outbreak, the research and development of vaccines, etc. are inseparable from the protection of human resources, which are the most valuable and scarce resources. Emergency logistics is the key to the timely and smooth arrival of rescue materials in the disaster area when an emergency occurs, and the talent guarantee of emergency logistics is the key to whether rescue workers can carry out rescue work in a timely manner. Small and medium-sized enterprises (SMEs) are small in scale and less able to withstand risks, so they are at a great disadvantage when dealing with emergencies. This paper is of great relevance to the study of emergency logistics and human resource management in SMEs. Through the case study method, this paper analyzes the problems of emergency logistics and human resource management in China in response to emergencies and proposes a series of solutions to these problems, hoping to inspire SMEs in response to emergencies.

\section{Conflicts of Interest}

The authors declare no conflicts of interest regarding the publication of this paper.

\section{References}

Alesch, D. J., Holly, J. N., Mittler, E., \& Nagy, R. (2001). Organizations at Risk: What Happens When Small Businesses and Not-for-Profits Encounter Natural Disasters (p. 
105). Fairfax, VA: Public Entity Risk Institute.

Brauner, C., Whrmann, A. M., Frank, K., \& Michel, A. (2019). Health and Work-Life Balance across Types of Work Schedules: A Latent Class Analysis. Applied Ergonomics, 81, Article ID: 102906. https://doi.org/10.1016/j.apergo.2019.102906

Greer, C. R., Lusch, R. F., \& Vargo, S. L. (2016). A Service Perspective: Key Managerial Insights from Service-Dominant (S-D) Logic. Organizational Dynamics, 45, 28-38. https://doi.org/10.1016/j.orgdyn.2015.12.004

Grnroos, C. (2006). Adopting a Service Logic for Marketing. Marketing Theory, 6, 317-333. https://doi.org/10.1177/1470593106066794

Groenroos, C. (2008). Service Logic Revisited: Who Creates Value? And Who Co-Creates? European Business Review, 20, 298-314. https://doi.org/10.1108/09555340810886585

Hui, C. (2014). The Main Problems and Optimization Suggestions of China's Emergency Logistics System. China Circulation Economy, 28, 20-24.

Luo, M. Q. (2019). Analysis of Vehicle Scheduling Strategy in Emergency Logistics Transportation. China Logistics and Purchasing, No. 14, 58.

Lusch, R. F., \& Vargo, S. L. (2012). The Forum on Markets and Marketing (fmm): Advancing Service-Dominant Logic. Marketing Theory, 12, 193-199.

https://doi.org/10.1177/1470593111429509

Lusch, R. F., Vargo, S. L., \& Wessels, G. (2008). Toward a Conceptual Foundation for Service Science: Contributions from Service-Dominant Logic. Ibm Systems Journal, 47, 5-14. https://doi.org/10.1147/sj.471.0005

Ou, Z. W., Li, K., Jiang, Y. H., Wang, H. Y., \& Gan, W. X. (2005). Research on Emergency Logistics Guarantee Mechanism. Logistics Technology, No. 9, 13-15.

Ou, Z. W., Wang, H. Y., Jiang, D., Lu, B. L., Gan, W. X., \& Liang, J. (2004). Emergency Logistics. Journal of Chongqing University (Natural Science Edition), 3, 164-167.

Ren, Y. L. (2016). Research on the Innovation of Human Resource Management in China's Enterprises under the Low Carbon Economy. Journal of Changjiang University (Social Science Edition), 39, 53-56.

Ruolan, Z., \& Yan, Z. (2020). Research on the Status Quo and Problems of Emergency Logistics Management of Public Health Emergencies. Logistics Science and Technology, 43, 72-74.

Smith, D. (1990). Beyond Contingency Planning: Towards a Model of Crisis Management. Industrial Crisis Quarterly, 4, 263-275. https://doi.org/10.1177/108602669000400402

Spillan, J., \& Hough, M. (2003). Crisis Planning in Small Businesses: Importance, Impetus and Indifference. European Management Journal, 21, 398-407. https://doi.org/10.1016/S0263-2373(03)00046-X

Vargo, S. L., \& Lusch, R. F. (2004). Evolving to a New Dominant Logic for Marketing. Journal of Marketing, 68, 1-17. https://doi.org/10.1509/jmkg.68.1.1.24036

Vargo, S. L., \& Lusch, R. F. (2008). From Goods to Service(s): Divergences and Convergences of Logics. Industrial Marketing Management, 37, 254-259. https://doi.org/10.1016/j.indmarman.2007.07.004

Xue, D. B. (2008). Flexible Work System, How Far Away from Us. Human Resources, No. 15, 42-45.

Yuan, Q., Zhang, J. X., \& Chen, Y. (2020). Concepts and Countermeasures for Establishing an Emergency Logistics System in China-Lessons Learned Based on the Prevention and Control of the COVID-19 Epidemic. Open Herald, No. 3, 86-92. 